\title{
Sobrevivência de Salmonella enteritidis em Maionese Caseira
}

Izabela Alves Gomes (II), Erika Fraga de Souza (I), Ana Paula de Oliveira Ribeiro (I), Vanessa Fiuza de Mello (I), Simone Duarte de Oliveira Costa (I), Janine Passos Lima da Silva (I)

(I) EMBRAPA - Embrapa Agroindústria de Alimentos (Av. das Américas, 29.501 Rio de JaneiroRJ, 23020-470), (II) UERJ - Universidade do Estado do Rio de Janeiro (Av. São Francisco Xavier, 524 Rio de Janeiro-RJ)

\section{Resumo}

A maionese de baixa acidez, conhecida como "maionese caseira" e amplamente consumida por pessoas que rejeitam o sabor acidificado da maionese industrial, é elaborada com ovo cru e apresenta $\mathrm{pH} \geq 4,20$, o que eleva o risco de contaminação por Salmonella Enteritidis para os seus consumidores. Uma das alternativas para melhorar a segurança da maionese caseira é utilizar óleo essencial de orégano como antimicrobiano natural, comprovadamente efetivo contra Salmonella Enteritidis (SE). Dessa forma, neste trabalho foi avaliada a sobrevivência de SE em maionese caseira formulada com óleo essencial de orégano (OEO). Para avaliação foi utilizada Salmonella Enteritidis ATCC 13076 reativada em caldo de cérebro e coração (BHB - Merck) a $30^{\circ} \mathrm{C}$ por 18 horas. $25 \mathrm{~mL}$ de solução salina contendo $10^{4} \mathrm{UFC} / \mathrm{mL}$ da cultura de SE foram inoculados em $225 \mathrm{~g}$ de maionese caseira contendo OEO $0,4 \%$. O procedimento foi repetido com maionese caseira sem $\mathrm{OEO}$, denominada amostra controle. Cada uma das misturas foi dividida em oito sacos estéreis em alíquotas de $25 \mathrm{~g}$, quatro das quais foram armazenadas a $8^{\circ} \mathrm{C}$ e quatro a $30^{\circ} \mathrm{C}$. Nos tempos 0,2 , 4 e 24 horas, um dos sacos foi submetido a três diluições decimais seriadas, que foram semeadas em superfície em ágar XLD (Xylose-Lysine-Desoxycholate Agar), em duplicata. Após 24 horas de incubação a $30^{\circ} \mathrm{C}$, efetuou-se a contagem das colônias nas placas de XLD e os resultados foram convertidos em log UFC/g de maionese. Como 
resultado, não houve contagem de colônias nas placas da amostra de maionese com OEO em todos os tempos avaliados. Para amostra de maionese caseira sem OEO, os resultados foram 3,20; 3,10; 3,18 e 3,09 log UFC/g de maionese para os tempos 0, 2, 4 e 24 horas respectivamente. Esses dados indicam que a SE sobreviveu somente na formulação de maionese caseira sem adição de óleo essencial de orégano. Com isso podese concluir que a utilização de OEO como antimicrobiano natural em maionese caseira aumenta a segurança no consumo desse produto.

Palavras-Chave: óleo essencial de orégano, antimicrobiano natural, maionese de baixa acidez

Agência de Fomento: EMBRAPA 